\title{
A More Generalizable Method to Evaluate Changes in Health Care Costs with Changes in Health Risks Among Employers of All Sizes
}

\author{
Shirley Musich, PhD, John White, DPM, MS, ${ }^{2}$ Stephen K. Hartley, BS, ${ }^{3}$ Gandhi R. Bhattarai, PhD, ${ }^{4}$ \\ Kevin Hawkins, $\mathrm{PhD}^{5}$ and Ronald J. Ozminkowski, $\mathrm{PhD}^{6}$
}

\begin{abstract}
The objective of this study was to estimate the association between changes in health care expenditures relative to changes in health risk status for employers of all sizes. Repeat health risk assessments (HRAs) were obtained from 50,005 employees and spouses with 2 years of health plan enrollment, and from 37,559 employees and spouses with 3 years of enrollment in employer-sponsored medical coverage. Changes in health care expenditures were measured from the year before completion of the first HRA to the years before and after the completion of the second HRA. Propensity score weighting was used to adjust for those who did not repeat the HRA so results could be extrapolated to the larger population. Propensity score weighted multiple regression analyses were used to estimate the relationship between changes in health care expenditures with changes in risk status for 9 risk categories. Significantly higher health care expenditures were associated with those who moved from low risk to medium or high risk, compared to those who remained low risk. Expenditure reductions estimated for those who improved their health status from high risk to medium or low risk were not statistically significant. This study is unique because of its large sample size, its use of data from a wide range of employer sizes, and its efforts to extend generalizability to those who did not complete both HRAs. These results demonstrate that the potential for short-term health care savings may be greater for programs that help maintain low risk than for programs focused on risk reduction. (Population Health Management 2014;17:297-305)
\end{abstract}

\section{Introduction}

$\mathbf{M}$ ANY EMPLOYERS SPONSOR employee health management programs to help contain health care costs. These programs include a wide range of educational and behavioral change efforts that are offered to employees and spouses across employers of all sizes. A 2010 national employer survey by the Kaiser Foundation found that $74 \%$ of employers offering health care benefits also sponsored at least 1 wellness program, an increase from $58 \%$ of employers in 2009. The Kaiser study noted that most of this change was driven by small employers adopting Web-based wellness resources in 2010. ${ }^{1}$ According to the US Census Bureau, at least $50 \%$ of all US employees work within small employer environments (ie, fewer than 500 employees). ${ }^{2}$ Nevertheless, although wellness options have continued to expand for employees of small to medium-sized firms, program evaluations and subsequent scientific reports tend to focus on medium and large employer groups. ${ }^{1,3,4}$

With the continued expansion of health management programming, there is an ongoing interest in documenting population health improvement and economic returns from these programmatic investments. Despite several decades of research on these topics, shortcomings in the research methods, small sample sizes, the use of single employer evaluations, a wide range of program designs, and a lack of consistency across studies have hampered conclusions about the effectiveness and/or cost-benefit of these programs. ${ }^{5}$ Numerous studies, most being cross-sectional in design, have documented that health risks are associated with higher health

\footnotetext{
${ }^{1}$ Advanced Analytics, Optum, Ann Arbor, Michigan.

${ }^{2}$ Health Economics Outcome Research, Optum, Minneapolis, Minnesota.

${ }^{3}$ Consumer Solutions Group, Optum, Phoenix, Arizona.

${ }^{4}$ Advanced Analytics Group, Optum, Rocky Hill, Connecticut.

${ }^{5}$ Advanced Analytics, Optum, Ann Arbor, Michigan.

${ }^{6}$ Consumer Solutions Group, Optum, Ann Arbor, Michigan.
} 
care expenditures in employee and spouse populations. ${ }^{6-13}$ Studies also show that health management programs of various designs may result in health improvements for selected health risks (eg, physical activity, nutrition, weight) and/or overall health risk status over time. ${ }^{14-19}$

Evaluations of the economic benefits resulting from health management programs are generally based on the hypothesis that high rates of participation are necessary to generate savings. Generally, it takes 3 to 5 years for such savings to materialize..$^{3,5,17,20,21}$ Fewer longitudinal studies have focused on the mechanism and/or timing of cost savings related to reductions of measured health risks and/or in the maintenance of those currently at low risk.

It is well documented in the scientific literature that costs positively correlate with changes in risks-as risks improve, health care costs often decrease and as risks get worse, costs tend to increase. ${ }^{22-26}$ More recently, studies have included larger populations, combined data from several large employers, and have increased the precision of the timing for cost changes following risk changes. ${ }^{18,19}$ To date, however, the authors of the present study could find no studies including small and medium-sized employers. In addition, methods have been lacking that would address selection bias related to having highly motivated repeat health risk assessment (HRA) participants. The purpose of this study is to estimate the association between changes in health care expenditures relative to changes in health risk status for employers of all sizes, generalizing to all employees and spouses regardless of whether an HRA was completed.

\section{Methods}

\section{Study design and sample selection}

This study was a retrospective cohort analysis using individuallevel, self-reported data obtained from 2 consecutive annual HRAs. These HRAs were completed by insured employees, spouses, and significant others from across Optum's employer client book of business. Inclusion criteria limited the study sample to those 18 to 63 years of age at their first HRA and to those who had completed their second HRAs between May 2009 and May 2011. The elapsed time between the first and second HRA must have been between 270 and 450 days. Most sample members had medical and pharmacy covered by UnitedHealthcare Insurance Company (84\%); another $16 \%$ were covered by other health plans. For the first analysis, HRA repeaters were continuously enrolled in their health plan for 2 years, with no monthly gaps from the year prior to the first HRA to the year prior to the second HRA. For the second analysis, HRA repeaters were continuously enrolled for 3 years, from the year before the first HRA was taken to the year after the second HRA was completed. Members with evidence of maternity services were excluded from this analysis. About $80 \%$ of employers offered additional health coaching options. To maintain a consistent program intensity across employee/spouse participant populations, those with documented health coaching participation also were excluded (about 20\%).

To minimize selection bias that might occur if HRA repeaters were significantly different than those who did not complete 2 HRAs, a cohort of insured employees and spouses who completed 0 or 1 HRA (ie, those who were eligible for but did not complete 2 HRAs) also was selected.
Their data were used to generate a propensity score case weight that was applied to those who completed 2 HRAs to make the data from those who completed 2 HRAs better resemble all employees regardless of whether HRAs were completed. Methods for generating the case weight are described in a following section. HRA non-completers/nonrepeaters must have otherwise met the same criteria as those with repeat HRAs to be included in the study.

\section{Definition of health risks}

The University of Michigan Health Management Research Center HRA was administered online and included questions about lifestyle and behavioral health risks, biometric factors, and health status. ${ }^{27}$ The following 9 health risks were included in this study: alcohol, blood pressure (BP), body weight, cholesterol, medication/drug use for relaxation, nutrition, physical activity, stress, and smoking. All survey responses were selfreported; however, values from biometric screenings were utilized if measured within 30 days of the HRA completion date, as occurred in about $10 \%$ of respondents. The 9 health risks were dichotomized to denote either higher risk and lower risk groups as follows: alcohol: $>14$ drinks/wk (men); $>7$ drinks/wk (women); BP: systolic BP $>119$ or diastolic BP $>$ $79 \mathrm{~mm} \mathrm{Hg}$; cholesterol: > $199 \mathrm{mg} / \mathrm{dL}$; drug use for relaxation: sometimes/almost every day; physical activity: $<1$ time/wk; smoking: current; nutrition: $<3$ servings/day fruit/vegetable/ fiber; stress: some/a lot; and weight: body mass index $<18.5$ or $>24.9$. Of note, the research team used at-risk categories that included those at moderate and high severity risk levels - an approach commonly used in population health management strategies. Based on the number of risk factors where the respondent was at higher health risk, individuals were subsequently grouped into the following overall risk status levels for the analysis: high risk indicates the individual was at higher risk for 4-9 risks, medium risk indicates he or she was at higher risk for 3 risk factors, and low risk indicates the respondent was at higher risk for $0-2$ risk factors. The research team then observed whether sample members moved between these low-, medium-, or high-risk categories over time. These movements were then associated with increases or decreases in health care expenditures by undertaking propensity score weighted statistical analyses that are described in a following section.

\section{Determinants of health care costs}

Total allowable health care expenditures were calculated in US dollars for each sample member, including all inpatient, outpatient, professional, and pharmacy costs, for the year prior to the first HRA, the year prior to the second HRA, and the year after the second HRA was completed. Allowed health care costs (including plan payment, member payment, and coordination of benefits) were utilized because allowed health care costs are impacted to a lesser degree by differences in employer health care paid benefit structures, or by changes in benefit structures that may occur over time. All health care costs were adjusted to May 2011 dollars using the medical care services component in the Consumer Price Index.

\section{Covariates}

Covariates were included in the weighted regression analyses to estimate relationships between changes in health care expenditures and changes in risk so that the research 
team could differentiate between the impact of changing risks versus other factors that also may influence health care expenditures. These covariates included measures of demographics, health status, and other characteristics self-reported on the HRA, or were taken from health plan eligibility and claims files. Demographic variables included measures of the respondent's age, sex, race, education level, employee status, and employer size. Age and education were each stratified into 4 groups (age: 18-34, 35-44, 45-54, and 55-63 years; education: high school graduate or less, some college, college graduate, and graduate school). Race was stratified into 5 groups (white, black, Hispanic, Asian, and other). Employer size was stratified into 3 groups by number of employees (small < 1000 employees; medium 1000-9999 employees; and large $\geq 10,000$ employees) and employee status was stratified into 2 groups (employee and spouse/significant others).

Covariates measured from health plan membership or claims data included the individual's health plan type, the ratio of paid-to-allowed health care costs covered by the respondents' insurance, an indicator of the existence of any diagnosis or procedure associated with complex medical conditions (see the following description) and the calculated Charlson comorbidity index (CCI). ${ }^{28}$ The CCI is a measure of the risk of 1-year all-cause mortality attributable to selected comorbidities that also has been shown to be highly predictive of morbidity and health care expenditures.

Information about health plan type was stratified into 4 groups: point of service (POS), preferred provider organization (PPO), exclusive provider organization (EPO), and other. The ratio of paid-to-allowed health care costs represented the "richness," or actuarial value, of the subjects' health plan benefit design. The actuarial value was calculated for each employer and assigned to each member. The complex medical condition flag was created to designate whether a member had at least one of the following complex conditions as determined by claims-based diagnoses or procedures during the HRA pre period: cancer, end-stage renal disease, HIV/ AIDS, organ transplant, trauma, or mental disorders.

\section{Propensity score weighting for selection bias adjustment}

Propensity score weighting was used to adjust for potential selection bias to enhance the generalizability of these findings to the broader population. The propensity score adjustment process uses information about the demographic, socioeconomic, and health status variables already described that could potentially drive HRA completion. This information was used to estimate the underlying probability of completing 2 HRAs for each individual, and then that estimated probability was used to create a weighting variable to be applied to the data from those who completed 2 HRAs to make them better resemble all employees regardless of the number of HRAs that were completed. The value of the weighting variable equals 1/predicted probability of completing 2 HRAs. These weighted analyses reduced threats to external validity that are problematic in other studies that do not adjust for response bias. The utility of propensity score models to adjust for external validity threats are described elsewhere. ${ }^{29}$ A practical application of these methods was demonstrated in a recent publication evaluating the associations between health risks and health care expenditures. ${ }^{13}$
One can make inferences about the utility of the propensity score approach by assessing the balance of measured member characteristics between HRA repeaters and non-completers/ non-repeaters. This can be done by comparing the standardized difference value for each covariate used in the propensity score weighting and observing how balance improves after weighting. Standardized difference values less than 0.10 indicate successful balancing of each variable between those who completed 2 HRAs and those who did not. If most variables have standardized difference values less than 0.10 this helps ensure that the study sample more closely resembles the overall population of HRA completers/non-completers/ non-repeaters, thereby increasing generalizability of the study findings when weighted statistical analyses are used. ${ }^{30}$

Finally, as a sensitivity analysis for the effectiveness of the propensity score weighting method, the research team also applied a 2-stage residual inclusion method suggested by Terza et $\mathrm{al}^{31}$ to adjust for selection bias. This method uses a 2-step regression model that adjusts for the impact of both measurable and nonmeasurable variables that may influence the likelihood of completing 2 HRAs. The Terza et al method is similar to the propensity score method in that both begin by using regression analyses to estimate relationships between completing 2 HRAs and the demographic and other variables already mentioned. Rather than creating a case weight for the subsequent health risk/health expenditure regression, however, the Terza et al approach uses the residuals from the HRA completion regression as another independent variable in the risk/cost regression.

\section{Outcome health care expenditure variable}

Changes in health care expenditures were calculated by subtracting the individual's baseline expenditures prior to the first HRA from (1) the annual expenditures prior to the second HRA, and (2) from the annual costs after the second HRA for each of the 9 risk status change categories. The resulting cost dfference variables were used as the dependent variables for the weighted risk/cost regressions described next.

\section{Regression modeling}

Propensity score weighted multiple regression analyses were performed to measure the independent association between the health care cost differences and each of the 9 risk status change categories, controlling for the impact of all of the covariates mentioned. Generalized linear regression models with a gamma distribution and a log link function were used to assess the association between risk status changes and changes in health care expenditures. ${ }^{32}$ Individuals whose total annual expenditures exceeded the 97.5th percentile were excluded from the analyses to avoid outlier values from heavily influencing the results.

\section{Results}

\section{Sample characteristics}

The study included 50,005 sample members when the focus was on health care expenditure changes between the year before the first HRA was taken and the year before the second HRA was taken. Sample sizes were lower $(n=37,559)$ when focusing on expenditure changes between 
the year before the first HRA was taken and the year after the second HRA. The unweighted demographics, health status, and other characteristics of sample members for these 2 sets of analyses were similar and are shown in Table 1 . The samples used in both analyses were predominantly employees, females, white, and well educated. Their aver-

Table 1. Demographic, Health Plan, Health Status, AND OTHER CHARACTERISTICS OF HRA REPEATERS

Sample Focused Sample Focused on Year Before on Year Before the First HRA the First HRA and Year Before and Year After the Second HRA the Second HRA $(\mathrm{n}=50,005) \quad(\mathrm{n}=37,559)$

(\%)

(\%)

\begin{tabular}{|c|c|c|}
\hline $\begin{array}{l}\text { Sex } \\
\quad \text { Female }\end{array}$ & 54.6 & 54.6 \\
\hline \multicolumn{3}{|l|}{ Age } \\
\hline 18 to 34 & 22.5 & 21.7 \\
\hline 35 to 44 & 29.1 & 28.9 \\
\hline 45 to 54 & 31.7 & 32.2 \\
\hline 55 to 63 & 16.8 & 17.3 \\
\hline \multicolumn{3}{|l|}{ Race } \\
\hline White & 77.3 & 77.5 \\
\hline Black & 8.5 & 8.1 \\
\hline Hispanic & 8.2 & 8.5 \\
\hline Asian & 4.3 & 4.2 \\
\hline Other & 1.7 & 1.8 \\
\hline \multicolumn{3}{|l|}{ Education } \\
\hline High School or less & 19.4 & 18.8 \\
\hline Some College & 27.2 & 27.1 \\
\hline College Grad & 37.2 & 37.7 \\
\hline Grad School & 16.3 & 16.4 \\
\hline \multicolumn{3}{|l|}{ Health Plan Type } \\
\hline POS & 61.5 & 71.7 \\
\hline PPO & 3.7 & 4.7 \\
\hline EPO & 15.1 & 18.1 \\
\hline Other & 19.6 & 5.4 \\
\hline \multicolumn{3}{|l|}{ Relationship } \\
\hline Employee & 82.8 & 85.4 \\
\hline \multicolumn{3}{|l|}{ Client Size } \\
\hline Small (1-1000) & 28.1 & 31.8 \\
\hline Medium (1000-9999) & 41.2 & 49.0 \\
\hline Large $(\geq 10,000)$ & 14.5 & 15.1 \\
\hline Unknown Size & 16.2 & 4.1 \\
\hline $\begin{array}{l}\text { Have a Health Care } \\
\text { Claim }\end{array}$ & 89.7 & 89.5 \\
\hline $\begin{array}{l}\text { Complex Medical } \\
\text { Conditions }\end{array}$ & 11.6 & 11.8 \\
\hline $\begin{array}{l}\text { Offered an HRA } \\
\text { Incentive }\end{array}$ & 25.3 & 28.7 \\
\hline $\begin{array}{l}\text { Client Allowed to Paid } \\
\text { Ratio }\end{array}$ & 0.81 & 0.81 \\
\hline CCI & 0.24 & 0.24 \\
\hline $\begin{array}{l}\text { Time Between HRAs } \\
\text { (days) }\end{array}$ & 362.5 & 361.6 \\
\hline
\end{tabular}

CCI, Charlson comorbidity index; EPO, exclusive provider organization; HRA, health risk assessment; POS, point of service; PPO, preferred provider organization. age age was about 44 years. Most members chose POS health plans. Health risk characteristics of sample members are shown in Table 2. For most risk factors there were small changes over time in percentages of sample members at high risk.

The results of propensity score weighting for response bias are shown in Table 3. Prior to propensity score weighting, repeat HRA completers were significantly older, more likely to be an employee, to have been offered an HRA incentive, and to be in a small or medium-sized organization. HRA repeaters also were less likely to have a medical plan that was a POS, PPO, or EPO. After propensity score weighting, differences between repeat HRA completers and non-completers/non-repeaters were minimized. Most variables had standardized differences less than 0.10 , indicating successful weighting. The many differences between the repeat HRA completers and non-completers/non-repeaters prior to weighting underscore the importance of this adjustment in order to make these results generalizable.

Tables 4 and 5 show the propensity score weighted changes in health care expenditures associated with each of the 9 risk status change categories, after controlling for demographics, medical plan type, health status, and baseline health risks. Differences in health care costs from the year before the first HRA to the year before the second HRA are shown in Table 4. Differences in health care costs from baseline to the year after the second HRA are shown in Table 5.

In both tables, health care expenditures are presented as unadjusted differences (ie, prior to any regression analyses); regression adjusted differences without any weighting; and propensity score weighted regression adjusted differences. Generally, the values are consistent regardless of the use of these approaches. The Terza et al model to adjust for selection bias provided nearly identical results when compared to the propensity score weighted results and thus are not shown but are available from the authors upon request. ${ }^{31}$

As shown in Table 4, significantly higher health care expenditures were associated with transitions to higher risk status (ie, moving from low to medium, low to high, or medium to high risk). Significant cost increases also were observed when comparing the year before the first HRA to the year after the second HRA was taken, when considering those who moved from low to medium risk and those who moved from low to high risk (Table 5). Conversely, those who improved their risk status by moving to lower risk categories (ie, from high to medium or high to low risk) demonstrated smaller cost increases compared to those who remained high risk. However, the changes in costs that were associated with reductions in risk were not statistically significant in either analysis. Finally, about $30 \%$ of the sample included those who were always in the lowest risk group; members of this group had the lowest increases in costs over time. Overall, 19\% improved their risk status, another $18 \%$ moved to a higher risk status through the addition of risk factors, $11 \%$ remained medium risk, and about $20 \%$ remained high risk over the time period (Tables 4 and 5).

\section{Discussion}

Sample members in this study of repeat HRA completers were from small, medium, and large employers. The shorter term economic impact of risk status changes indicated 
Table 2. Health Risk Changes Over Time

\begin{tabular}{|c|c|c|c|c|c|c|}
\hline \multirow[b]{2}{*}{ Health Risks } & \multicolumn{3}{|c|}{$\begin{array}{l}\text { Sample Focused on Year Before } \\
\text { the First HRA and Year Before } \\
\text { the Second HRA }(\mathrm{n}=50,005)\end{array}$} & \multicolumn{3}{|c|}{$\begin{array}{l}\text { Sample Focused on Year Before } \\
\text { the First HRA and Year After } \\
\text { the Second HRA }(\mathrm{n}=37,559)\end{array}$} \\
\hline & $\begin{array}{l}\text { First HRA } \\
(\%)\end{array}$ & $\begin{array}{c}\text { Second HRA } \\
(\%)\end{array}$ & Change & $\begin{array}{c}\text { First HRA } \\
(\%)\end{array}$ & $\begin{array}{c}\text { Second HRA } \\
(\%)\end{array}$ & Change \\
\hline \multicolumn{7}{|l|}{ BMI } \\
\hline 15.0-18.4 (underweight) & 0.9 & 0.8 & -0.1 & 0.9 & 0.8 & -0.1 \\
\hline $18.5-24.9$ (normal) & 33.7 & 33.6 & -0.1 & 32.4 & 32.4 & 0.0 \\
\hline $25.0-29.9$ (overweight) & 36.1 & 36.4 & 0.3 & 36.1 & 36.3 & 0.2 \\
\hline $30.0-39.9$ (obese) & 24.9 & 24.8 & -0.1 & 25.9 & 25.8 & -0.1 \\
\hline 40.0-55.0 (morbidly obese) & 4.4 & 4.4 & 0.0 & 4.7 & 4.7 & 0.0 \\
\hline \multicolumn{7}{|l|}{ Blood Pressure } \\
\hline $\mathrm{SBP} / \mathrm{DBP}<120 / 80 \mathrm{~mm} \mathrm{Hg}$ & 50.1 & 45.2 & -4.9 & 49.5 & 44.4 & -5.0 \\
\hline SBP $120-139$ or DBP $80-89 \mathrm{~mm} \mathrm{Hg}$ & 39.7 & 44.9 & 5.2 & 40.0 & 45.5 & 5.4 \\
\hline $\mathrm{SBP}>139$ or $\mathrm{DBP}>89 \mathrm{~mm} \mathrm{Hg}$ & 10.2 & 9.9 & -0.3 & 10.5 & 10.1 & -0.4 \\
\hline \multicolumn{7}{|l|}{ Cholesterol } \\
\hline $130-199 \mathrm{mg} / \mathrm{dL}$ & 78.4 & 77.3 & -1.1 & 78.0 & 76.9 & -1.1 \\
\hline $200-239 \mathrm{mg} / \mathrm{dL}$ & 12.7 & 14.5 & 1.8 & 12.8 & 14.6 & 1.8 \\
\hline$>239 \mathrm{mg} / \mathrm{dL}$ & 8.9 & 8.3 & -0.7 & 9.2 & 8.5 & -0.7 \\
\hline \multicolumn{7}{|l|}{ Smoking } \\
\hline Never & 69.6 & 67.7 & -1.9 & 69.8 & 67.8 & -2.0 \\
\hline Former & 22.3 & 24.5 & 2.2 & 22.1 & 24.4 & 2.3 \\
\hline Current & 8.0 & 7.8 & -0.3 & 8.1 & 7.8 & -0.3 \\
\hline \multicolumn{7}{|l|}{ Alcohol } \\
\hline $\begin{array}{l}>14 \text { drinks/wk (men); > } 7 \text { drinks/wk } \\
\text { (women) }\end{array}$ & 3.0 & 2.8 & -0.2 & 2.9 & 2.7 & -0.2 \\
\hline \multicolumn{7}{|l|}{ Nutrition (Fruit/Veg/Fiber) } \\
\hline 5-6 servings per day & 16.2 & 16.5 & 0.3 & 15.9 & 16.3 & 0.4 \\
\hline $3-4$ servings per day & 46.7 & 47.5 & 0.7 & 46.8 & 47.4 & 0.6 \\
\hline $1-2$ servings per day & 35.2 & 34.5 & -0.6 & 35.4 & 34.8 & -0.6 \\
\hline Rarely/never & 2.0 & 1.5 & -0.5 & 1.9 & 1.5 & -0.4 \\
\hline \multicolumn{7}{|l|}{ Stress Impacted Health } \\
\hline None & 20.9 & 21.7 & 0.8 & 20.1 & 21.1 & 0.9 \\
\hline Hardly Any & 40.1 & 40.3 & 0.2 & 40.3 & 40.3 & 0.0 \\
\hline Some & 33.1 & 32.3 & -0.9 & 33.6 & 33.0 & -0.7 \\
\hline A Lot & 5.9 & 5.7 & -0.2 & 5.9 & 5.7 & -0.2 \\
\hline \multicolumn{7}{|l|}{ Drug Use For Relaxation } \\
\hline Rarely/Never & 86.6 & 86.2 & -0.3 & 86.5 & 86.3 & -0.3 \\
\hline Sometimes & 4.0 & 4.0 & 0.0 & 4.0 & 4.0 & 0.0 \\
\hline Almost Every Day & 9.5 & 9.8 & 0.3 & 9.5 & 9.8 & 0.3 \\
\hline \multicolumn{7}{|l|}{ Physical Activity } \\
\hline 3 or more times per week & 59.6 & 60.4 & 0.8 & 58.7 & 59.9 & 1.2 \\
\hline $1-2$ times per week & 27.3 & 27.8 & 0.5 & 27.8 & 28.2 & 0.4 \\
\hline$<1$ time per week & 13.1 & 11.8 & -1.3 & 13.5 & 12.0 & -1.6 \\
\hline \multicolumn{7}{|l|}{ Count of Risk (Categories) } \\
\hline Low Risk (0-2 risks) & 42.8 & 43.1 & 0.3 & 41.8 & 42.3 & 0.5 \\
\hline Moderate Risk (3 risks) & 26.6 & 26.5 & -0.2 & 26.8 & 26.6 & -0.2 \\
\hline High Risk (4-9 risks) & 30.6 & 30.4 & -0.2 & 31.5 & 31.1 & -0.3 \\
\hline
\end{tabular}

BMI, body mass index; DBP, diastolic blood pressure; HRA, health risk assessment; SBP, systolic blood pressure.

significant increases in health care expenditures associated with those who transitioned from low risk to either medium or high risk. These cost increases persisted and increased in the year after the second HRA was completed. Although smaller cost increases were directionally associated with risk status improvement compared to those who remained high risk (ie, moving from high risk to medium or low risk), these cost changes were not significant. Regression adjustment and adjustments for selection bias did not change these conclusions. Thus, these results would indicate that the cost savings potential associated with health management programs may be enhanced with an increased focus on the avoidance of gaining more risks.

This analysis utilized 9 health risks commonly used in the health promotion industry to estimate health status (eg, low, medium, and high risk) in the population studied. ${ }^{10-12,15,18,27}$ In implementing a population health management strategy, however, the research team included both moderate and high severity criteria in defining each of the individual health risks. This approach better stratifies the population for low- and 
Table 3. Propensity Score Weighting for Response Bias to Reduce Differences Between Those Who Completed Two HRAs and Those Who Did Not to Enhance the Generalizability of Results

\begin{tabular}{|c|c|c|c|c|c|c|}
\hline \multirow[b]{2}{*}{$\begin{array}{l}\text { Year of Change } \\
\text { Characteristic }\end{array}$} & \multicolumn{3}{|c|}{ Before Propensity Score Weighting } & \multicolumn{3}{|c|}{ After Propensity Score Weighting } \\
\hline & $\begin{array}{l}1 \text { or } 0 \text { HRA } \\
\text { Completers }\end{array}$ & $\begin{array}{c}2 \text { HRA } \\
\text { Completers }\end{array}$ & $\begin{array}{l}\text { Standardized } \\
\text { Difference }\end{array}$ & $\begin{array}{l}1 \text { or } 0 \text { HRA } \\
\text { Completers }\end{array}$ & $\begin{array}{c}2 \text { HRA } \\
\text { Completers }\end{array}$ & $\begin{array}{l}\text { Standardized } \\
\text { Difference }\end{array}$ \\
\hline Sample Number & $3,534,107$ & 50,005 & & $3,534,107$ & 50,005 & \\
\hline Age (years) & 41.7 & 43.5 & 0.154 & 41.7 & 43.4 & 0.145 \\
\hline \multicolumn{7}{|l|}{ Age Groups (\%) } \\
\hline $18-34$ & 31.1 & 22.5 & 0.196 & 31.0 & 25.9 & 0.114 \\
\hline $35-44$ & 24.1 & 29.1 & 0.112 & 24.2 & 26.2 & 0.046 \\
\hline $45-54$ & 25.6 & 31.7 & 0.136 & 25.6 & 27.9 & 0.052 \\
\hline $55-64$ & 19.2 & 16.8 & 0.063 & 19.2 & 20.0 & 0.022 \\
\hline Female $(\%)$ & 51.8 & 54.6 & 0.056 & 51.8 & 53.0 & 0.023 \\
\hline Have a Health Care Claim (\%) & 87.5 & 89.7 & 0.070 & 87.6 & 88.8 & 0.039 \\
\hline Complex Medical Condition (\%) & 13.7 & 11.6 & 0.065 & 13.7 & 13.5 & 0.005 \\
\hline \multicolumn{7}{|l|}{ Medical Plan Type (\%) } \\
\hline POS & 70.4 & 61.5 & 0.187 & 70.2 & 71.3 & 0.023 \\
\hline EPO & 16.9 & 15.1 & 0.049 & 16.9 & 13.4 & 0.098 \\
\hline PPO & 5.0 & 3.7 & 0.062 & 5.0 & 7.5 & 0.104 \\
\hline Other & 7.7 & 19.6 & 0.350 & 7.9 & 7.9 & 0.001 \\
\hline Offered an HRA Incentive (\%) & 20.2 & 25.3 & 0.120 & 20.3 & 36.8 & 0.372 \\
\hline Employee Status (\% EE) & 64.0 & 82.8 & 0.435 & 64.2 & 67.0 & 0.060 \\
\hline \multicolumn{7}{|l|}{ Employer Size (\%) } \\
\hline$<1000$ & 17.0 & 28.1 & 0.267 & 17.2 & 19.8 & 0.067 \\
\hline 1000-9999 & 35.4 & 41.2 & 0.119 & 35.5 & 40.2 & 0.096 \\
\hline$\geq 10,000$ & 36.2 & 14.5 & 0.514 & 35.9 & 35.5 & 0.008 \\
\hline Unknown & 11.4 & 16.2 & 0.140 & 11.5 & 4.6 & 0.255 \\
\hline
\end{tabular}

EE, employee; EPO, exclusive provider organization; HRA, health risk assessment POS, point of service; PPO, preferred provider organization.

high-level interventions. The study population had access to annual HRAs and a health communications program and demonstrated a small but nonsignificant improvement in the percentage $(+0.3$ percentage points $)$ of individuals at low risk over time. This net change in health status for the population reflects an overall $19 \%$ of the population that im- proved their risk status, $18 \%$ who got worse (ie, added health risks), and 63\% who stayed at the same risk level. Edington's natural flow model detailed in Loeppke et $\mathrm{al}^{15}$ indicates an expectation of a loss of 5 percentage points for those at low risk, with $16 \%$ expected to improve their health status, $23 \%$ to add health risks, and $61 \%$ to stay at the same risk levels.

Table 4. Changes in Health Care Expenditures Associated with Changes in Risks When Focusing on the Year Before the First HRA Was Taken and the Year Before the Second HRA Was Taken (N=50,005)

\begin{tabular}{|c|c|c|c|c|c|c|c|c|c|}
\hline \multirow[b]{2}{*}{$\begin{array}{l}\text { Time } 1 \\
\text { Risk }\end{array}$} & \multirow[b]{2}{*}{$\begin{array}{c}\text { Time } 2 \\
\text { Risk }\end{array}$} & \multirow[b]{2}{*}{$\mathrm{N}$} & \multicolumn{7}{|c|}{ Annual Health Care Expenditures and Cost Differences } \\
\hline & & & $\begin{array}{c}\text { Year } \\
\text { Before } \\
\text { First HRA } \\
\text { Cost }(\$)\end{array}$ & $\begin{array}{l}\text { Year } \\
\text { Before the } \\
\text { Second } \\
\text { HRA (\$) }\end{array}$ & $\begin{array}{c}\text { Unadjusted } \\
\text { Cost } \\
\text { Difference } \\
(\$)\end{array}$ & $\begin{array}{c}\text { *Adjusted Cost } \\
\text { Difference, Without } \\
\text { Propensity Score } \\
\text { Weighting }(\$)\end{array}$ & $\begin{array}{c}\mathrm{P} \\
\text { value }\end{array}$ & $\begin{array}{c}\text { Adjusted Cost } \\
\text { Difference After } \\
\text { Propensity Score } \\
\text { Weighting }(\$)\end{array}$ & $\begin{array}{c}\mathrm{P} \\
\text { value }\end{array}$ \\
\hline High Risk & High & 10,131 & 4096 & 4346 & 250 & 239 & Ref & 235 & Ref \\
\hline \multirow[t]{2}{*}{$\mathrm{N}=15,290$} & Medium & 3624 & 3451 & 3550 & 99 & 149 & 0.35 & 120 & 0.24 \\
\hline & Low & 1535 & 3424 & 3589 & 165 & 121 & 0.39 & 170 & 0.64 \\
\hline $\begin{array}{c}\text { Medium } \\
\text { Risk }\end{array}$ & High & 3578 & 3259 & 3577 & 318 & 339 & 0.05 & 380 & 0.02 \\
\hline \multirow[t]{2}{*}{$\mathrm{N}=13,319$} & Medium & 5553 & 2734 & 2900 & 166 & 154 & Ref & 156 & Ref \\
\hline & Low & 4188 & 2715 & 2907 & 193 & 192 & 0.68 & 157 & 0.99 \\
\hline Low Risk & High & 1498 & 2905 & 3497 & 592 & 511 & 0.0006 & 725 & $<.0001$ \\
\hline \multirow{2}{*}{$\mathrm{N}=21,396$} & Medium & 4055 & 2662 & 2836 & 174 & 191 & 0.34 & 252 & 0.045 \\
\hline & Low & 15,843 & 2412 & 2526 & 114 & 118 & Ref & 99 & Ref \\
\hline
\end{tabular}

*Adjusted for age, sex, race, education, all baseline risks, medical plan type, client-based paid/allowed ratio, elapsed time between HRAs, baseline Charlson comorbidity index, complex medical conditions (during T1 and T2), client size, and employee status.

HRA, health risk assessment. 
Table 5. Changes in Health Care Expenditures Associated with Changes in Risks When Focusing on the Year Before the First HRA Was Taken and the Year After the Second HRA Was TaKen $(\mathrm{N}=37,559)$

\begin{tabular}{|c|c|c|c|c|c|c|c|c|c|}
\hline \multirow[b]{2}{*}{$\begin{array}{l}\text { Time } \\
1 \text { Risk }\end{array}$} & \multirow[b]{2}{*}{$\begin{array}{l}\text { Time } \\
2 \text { Risk }\end{array}$} & \multirow[b]{2}{*}{$\mathrm{N}$} & \multicolumn{7}{|c|}{ Annual Health Care Expenditures and Cost Differences } \\
\hline & & & $\begin{array}{c}\text { Year } \\
\text { Before } \\
\text { First HRA } \\
\text { Cost }(\$)\end{array}$ & $\begin{array}{l}\text { Year } \\
\text { After the } \\
\text { Second } \\
\text { HRA }(\$)\end{array}$ & $\begin{array}{l}\text { Unadjusted } \\
\text { Cost } \\
\text { Difference } \\
(\$)\end{array}$ & $\begin{array}{c}\text { *Adjusted Cost } \\
\text { Difference, Without } \\
\text { Propensity Score } \\
\text { Weighting }(\$)\end{array}$ & $\begin{array}{c}\mathrm{P} \\
\text { value }\end{array}$ & $\begin{array}{c}\text { Adjusted Cost } \\
\text { Difference After } \\
\text { Propensity Score } \\
\text { Weighting }(\$)\end{array}$ & $\begin{array}{c}\mathrm{P} \\
\text { value }\end{array}$ \\
\hline High Risk & High & 7830 & 4140 & 4665 & 525 & 492 & Ref & 445 & Ref \\
\hline \multirow[t]{2}{*}{$N=11,818$} & Medium & 2796 & 3545 & 3852 & 307 & 394 & 0.42 & 348 & 0.42 \\
\hline & Low & 1192 & 3472 & 3694 & 222 & 233 & 0.13 & 278 & 0.32 \\
\hline Medium Risk & High & 2729 & 3305 & 3682 & 377 & 352 & 0.78 & 334 & 0.5100 \\
\hline \multirow{2}{*}{$\mathrm{N}=10,059$} & Medium & 4183 & 2803 & 3174 & 371 & 386 & Ref & 415 & Ref \\
\hline & Low & 3147 & 2693 & 3049 & 356 & 358 & 0.81 & 371 & 0.69 \\
\hline Low Risk & High & 1137 & 3012 & 3731 & 718 & 618 & 0.008 & 877 & $<.0001$ \\
\hline \multirow[t]{2}{*}{$\mathrm{N}=15,682$} & Medium & 3014 & 2630 & 3001 & 370 & 349 & 0.22 & 434 & 0.01 \\
\hline & Low & 11,531 & 2416 & 2632 & 216 & 231 & Ref & 197 & Ref \\
\hline
\end{tabular}

*Adjusted for age, sex, race, education, all baseline risks, medical plan type, client-based paid/allowed ratio, elapsed time between HRAs, baseline Charlson comorbidity index, complex medical conditions (during T1 and T2), client size, and employee status.

HRA, health risk assessment.

This would indicate that a low intensity health management program such as described in the present study can improve on the natural flow by assisting individuals to maintain their current health status and minimize transitions to higher risk status.

Expanding health risk criteria to include moderate severity better stratifies the population for interventions but lessens the impact on medical expenditures at baseline and in observed changes in medical expenditures with changes in those health risks over time. This may partially explain the results that risk reduction from high-risk status to medium or low risk was associated with smaller cost increases compared to those who remained high risk, but not actual cost decreases. Slowing medical cost increases in the current health economic environment could be considered a wineven without actual cost decreases.

In addition, the impact of gaining and losing health risks over time on health care expenditures has been demonstrated elsewhere. For example, the impact of weight gain on members of employer health plans has been associated with significantly increased health care expenditures, ${ }^{19,25}$ whereas weight loss (even in successful weight loss programs) was not associated with health care cost reductions within the next 2 years. ${ }^{16}$ In a large study by Carls et al, ${ }^{19}$ individual risk changes were tracked for 9 health risks over 3 years. Seven of the individual health risks that were reduced were not associated with lower health care expenditures while alcohol reduction and smoking cessation were associated with significantly increased costs. Haynes et $\mathrm{al}^{26}$ tracked 5 health risk transitions, confirming that individual risk reductions and overall risk status improvement were not associated with expected cost decreases over the time period. In fact, several of the risks that were reduced were associated with significant cost increases, as health issues may have motivated the changes in lifestyle (eg, smoking cessation, BP reduction).

The timing of health care cost changes relative to risk status changes has less often been the focus of scientific research studies. This study design increased the precision of these calculations by using a baseline year prior to the completion of the first HRA and then considered cost changes from the baseline to the year prior to the second HRA, or from the baseline to the year after the second HRA was completed. The precision of the design confirmed the results that significant increases in health care expenditures were associated with increased risks documented in the year before the second HRA and, furthermore, that these cost increases were significantly sustained in the year after the second HRA. In contrast, although health care expenditure increases were minimized over time with risk reduction documented in the year before the second HRA, these smaller cost increases were not statistically significant either in the year before or after the second HRA.

One of the issues often raised about analyses of relationships between changes in health risks and associated changes in health expenditures is whether the results are influenced by selection bias. If so, the results obtained may not generalize to those people who complete fewer than 2 HRAs. In the present study, only about $2 \%$ of the employees and spouses of interest completed 2 HRAs. To address this concern, the research team tested 2 adjustment approaches. One was based on propensity score weighting ${ }^{29}$; the other was a more recently developed residual inclusion method ${ }^{31}$ that is suitable when nonlinear relationships may exist, such as those between risks and costs. Both sets of results showed a similar pattern of findings. The research team urges some caution when interpreting these results because such a large proportion of people had fewer than 2 HRAs, so the adjustments that were applied may not have worked as well as would be the case if many more had completed 2 HRAs.

One of the strengths of this study is the large, diverse sample, which came from multiple employers of all sizes. Smaller employers often depend on the availability of health programs from their health insurance providers but represent a significant portion of the market and are responsible for much of the recent growth in wellness opportunities being presented to employees. ${ }^{1}$ To date, most research studies evaluating the impact of health management programs have focused on one or only a few large employers. This study provides an important addition to 
the health promotion literature in that employees from smaller companies (1-1000) are duly represented; they accounted for $28 \%$ of the study sample.

Limitations to consider include that the study results were based primarily on self-reported HRA data. Previous research has established the reliability and validity of HRA data, certainly for use in categorizing individuals into lowrisk or at-risk subgroups. ${ }^{33,34} \mathrm{~A}$ second limitation is that the adjustments for selection bias may be imperfect. With only a small proportion of people completing 2 HRAs, it is still possible that some unmeasured variables may influence the results and the ability to generalize to the entire population still may be somewhat limited. A third limitation relates to the relatively high level of education of this study cohort (54\% had at least a college degree), which may limit the generalizability of these results to populations from other employers.

A strength of this study is its large sample size of members with repeat HRAs that included employees, spouses, and significant others, associated with a wide range of employer sizes. A second strength is the use of the multivariate modeling, which controlled for several relevant confounding variables. A third strength is the adjustment for selection bias, though, while not likely to be perfect, was at least attempted and seems to be the first of its kind in this body of literature.

The research team found that health risks significantly affected health care expenditures across employers small to large. Furthermore, as health risks increased, health care expenditures significantly increased over time. These results underscore the potential opportunities for cost savings among employers of all sizes by focusing not only on reducing behavioral risks in susceptible individuals but perhaps more importantly by assisting those currently low-risk individuals to maintain their low-risk status over time.

Most insurance providers offer HRAs and other (eg, disease management) program features, thus program opportunities should be available across most employers either as employerfunded health management programs or as a benefit for those with insurance coverage. These results would indicate that efforts to avoid future health risks, along with health improvement opportunities, would be beneficial to employees in improved quality of life and well-being, and to their employers in maximizing the potential of health management programs as one strategy in the containment of health care costs.

\section{Acknowledgments}

The authors thank Frank G. Bottone, Jr, PhD for his critical review of this manuscript and editorial assistance.

\section{Author Disclosure Statement}

Drs. Musich, Bhattarai, Hawkins, and Ozminkowski, Mr. White, and Mr. Hartley declared the following potential conflicts of interest with respect to the research, authorship, and/or publication of this article: All authors are employees of Optum. Drs. Ozminkowski and Hawkins disclose that their positions with the company afford them stock options with UnitedHealth Group. This study was sponsored by Optum.

\section{References}

1. Kaiser Family Foundation. Employer health benefits: 2010 annual survey. Menlo Park, CA: The Kaiser Family Foundation, 2010.

2. US Census Bureau. Statistics about business size (including small business). Available at: <http://www.census.gov/econ/ smallbus.html >. Accessed July 27, 2013.

3. Baicker K, Cutler D, Song Z. Workplace wellness programs can generate savings. Health Aff (Millwood) 2010; 29:304-311.

4. Mattke S, Schnyer C, Van Busum KR. A review of the US workplace wellness market. Available at: < http://www.dol .gov/ebsa/pdf/workplacewellnessmarketreview2012.pdf $>$. Accessed July 24, 2013.

5. Lerner D, Rodday AM, Cohen JT, Rogers WH. A systematic review of the evidence concerning the economic impact of employee-focused health promotion and wellness programs. J Occup Environ Med 2013;55:209-222.

6. Anderson D, Whitmer RW, Goetzel RZ, et al. The relationship between modifiable health risks and group-level health care expenditures. Am J Health Promot 2000;15: 45-52.

7. Kowlesar NM, Goetzel RZ, Carls GS, Tabrizi MJ, Guindon A. The relationship between 11 health risk and medical and productivity costs for a large employer. J Occup Environ Med 2011;53:468-477.

8. Goetzel RZ, Carls GS, Wang S, et al. The relationship between modifiable health risk factors and medical expenditures, absenteeism, short-term disability, and presenteeism among employees at Novartis. J Occup Environ Med 2009;51:487-499.

9. Yen L, Schultz, A, Schnueringer E, Edington D. Financial costs due to excess health risks among active employees of a utility company. J Occup Environ Med 2006;48:896905.

10. Goetzel RZ, Anderson DR, Whitmer RW, Ozminkowski RJ, Dunn RL, Wasserman J. The relationship between modifiable health risks and health care expenditures. An analysis of the multi-employer HERO health risk and cost database. J Occup Environ Med 1998;40:843-854.

11. Pronk NP, Goodman MJ, O’Connor PJ, Martinson BC. Relationship between modifiable health risks and shortterm health care charges. JAMA 1999;282:2235-2239.

12. Goetzel RZ, Pei X, Tabrizi MJ, et al. Ten modifiable health risk factors are linked to more than one-fifth of employeremployee health care spending. Health Aff (Millwood) 2012;31:2472-2484.

13. White J, Hartley SK, Musich S, Hawkins K, Ozminkowski RJ. A more generalizable method to evaluation the association between commonly reported health risks and healthcare expenditures among employers of all sizes. J Occup Environ Med 2013;55:1179-1185.

14. Soler RE, Leeks KD, Razi S, et al. A systematic review of selected interventions for worksite health promotion. The assessment of health risks and feedback. Am J Prev Med 2010;38(2 suppl):S237-S262.

15. Loeppke R, Edington DW, Beg S. Impact of the prevention plan on employee health risk reduction. Popul Health Manag 2010;13:275-284.

16. Finkelstein EA, Linnan LA, Tate DF, Leese PJ. A longitudinal study on the relationship between weight loss, medical expenditures, and absenteeism among overweight employees in the WAY to Health study. J Occup Environ Med 2009;51:1367-1379. 
17. Milani RV, Lavie CJ. Impact of worksite wellness intervention on cardiac risk factors and one-year health care costs. Am J Cardiol 2009;104:1389-1392.

18. Nyce S, Grossmeier J, Anderson DR, Terry PE, Kelley B. Association between changes in health risk status and changes in future health care costs. J Occup Environ Med 2012;54:1364-1373.

19. Carls GS, Goetzel RZ, Henke RM, Bruno J, Isaac F, McHugh J. The impact of weight gain or loss on health care costs for employees at Johnson \& Johnson family of companies. J Occup Environ Med 2011;53:8-16.

20. Naydeck BL, Person JA, Ozminkowski RJ, Day BT, Goetzel RZ. The impact of the Highmark employee wellness programs on 4-year health care costs. J Occup Environ Med 2008;50:146-156.

21. Serxner S, Alberti A, Weinberger S. Medical cost savings for participants and nonparticipants in health risk assessments, lifestyle management, disease management, depression management and nurseline in a large financial services corporation. Am J Health Promot 2012;26:245-252.

22. Edington DW, Yen LT, Witting P. The financial impact of changes in person health practices. J Occup Environ Med 1997;39:1037-1046.

23. Schultz AB, Edington DW. The association between changes in metabolic syndrome and changes in cost in a workplace population. J Occup Environ Med 2009;51:771-779.

24. Martinson BC, Crain AL, Pronk NP, O'Connor PJ, Maciosek MV. Changes in physical activity and short term changes in health care charges: a prospective cohort study of older adults. Prev Med 2003;37:319-326.

25. Elmer PJ, Brown JB, Nichols GA, Oster G. Effects of weight gain on medical costs. Int J Obesity 2004;28:1365-1375.

26. Haynes G, Dunnagan T. Comparing changes in health risk factors and medical costs over time. Am J Health Promot 2002;17:112-121.
27. Edington DW. Emerging research: a view from one research center. Am J Health Promot 2001;15:341-349.

28. Charlson ME, Pompei P, Ales KL, MacKenzie CR. A new method of classifying prognostic comorbidity in longitudinal studies: development and validation. J Chronic Dis 1987;40:373-383.

29. Faries DE, Leon AC, Haro JM, Obenchain RL. Analysis of observational healthcare data using SAS. Cary, NC: SAS Institute, Inc., 2010.

30. Austin PC. A tutorial and case study in propensity score analysis: an application to estimating the effect of in-hospital smoking cessation counseling on mortality. Multivariate Behav Res 2011;46:119-151.

31. Terza JV, Basu A, Rathouz PJ. Two-stage residual inclusion estimation: addressing endogeneity in health econometric modeling. J Health Econ 2008;27:531-543.

32. Diehr P, Yanez D, Ash A, Hornbrook M, Lin DY. Methods for analyzing health care utilization and costs. Annu Rev Public Health 1999;20:125-144.

33. Anderson DR, Staufacker MJ. The impact of worksite-based health risk appraisal on health-related outcomes: a review of the literature. Am J Health Promot 1996;10:499-508.

34. Short ME, Goetzel RZ, Pei X, et al. How accurate are selfreports? Analysis of self-reported health care utilization and absence when compared with administrative data. J Occup Environ Med 2009;51:786-796.

Address correspondence to: John White, DPM, MS Health Economics Outcome Research Optum

PO Box 9472, NC975-1000

Minneapolis, MN 55440-9472

E-mail: john.white@optum.com 
This article has been cited by:

1. Andrei Dan, Marylise Boutros, Hacene Nedjar, Uri Kopylov, Waqqas Afif, Maria Abou Khalil, Elham Rahme. 2017. Cost of Ulcerative Colitis in Quebec, Canada. Inflammatory Bowel Diseases 23:8, 1262-1271. [Crossref]

2. Musich Shirley, Wang Shaohung, Hawkins Kevin, Klemes Andrea. 2016. The Impact of Personalized Preventive Care on Health Care Quality, Utilization, and Expenditures. Population Health Management 19:6, 389-397. [Abstract] [Full Text HTML] [Full Text PDF] [Full Text PDF with Links]

3. John M. Dement, Carol Epling, Julie Joyner, Kyle Cavanaugh. 2015. Impacts of Workplace Health Promotion and Wellness Programs on Health Care Utilization and Costs. Journal of Occupational and Environmental Medicine 57:11, 1159-1169. [Crossref]

4. Shirley Musich, Tre' McCalister, Sara Wang, Kevin Hawkins. 2015. An Evaluation of the Well at Dell Health Management Program: Health Risk Change and Financial Return on Investment. American Journal of Health Promotion 29:3, 147-157. [Crossref] 